\title{
Special issue on Regulation of the Photosynthetic Systems in honor of Tingyun Kuang
}

\author{
Congming $\mathrm{Lu}^{1} \cdot$ Jian-Ren Shen ${ }^{1,2} \cdot$ Lixin Zhang ${ }^{1}$
}

Published online: 9 September 2015

(C) Springer Science+Business Media Dordrecht 2015

This special issue of Photosynthesis Research is dedicated to 'Regulation of the Photosynthetic Systems,' which was the topic of a conference held during August 16-20, 2014 at Guilin, China. This conference was held in honor of Professor Tingyun Kuang (Fig. 1) at the occasion of her 80th birthday, for her continuous contributions and enthusiasm to the photosynthesis research, and in particular for the leading roles she played in this research field in China.

Tingyun Kuang has been dedicated to photosynthesis research in the Institute of Botany, the Chinese Academy of Sciences (IBCAS) since 1962, where she became a group leader a few years later, and is still a professor there at present. She was born in Zizhong County, Sichuan Province of China in 1934, where she completed her elementary and middle school study. She graduated from Department of Soil Agricultural Chemistry, Peking Agricultural University (now China Agricultural University) in 1956, and obtained a Ph.D. degree in biology from the Moscow State University in 1962. She worked as a visiting scholar in Charles J. Arntzen's Laboratory at Michigan State University from 1980 to 1981 on the isolation and

Congming Lu

lucm@ibcas.ac.cn

Jian-Ren Shen

shen@cc.okayama-u.ac.jp

Lixin Zhang

zhanglixn@ibcas.ac.cn

1 Photosynthesis Research Center, Key Laboratory of Photobiology Institute of Botany, Chinese Academy of Sciences, Beijing 100093, China

2 Department of Biology, Faculty of Science, Photosynthesis Research Center, Graduate School of Natural Science and Technology, Okayama University, 1-1, Naka 3-Chome, Tsushima, Okayama 700-8530, Japan

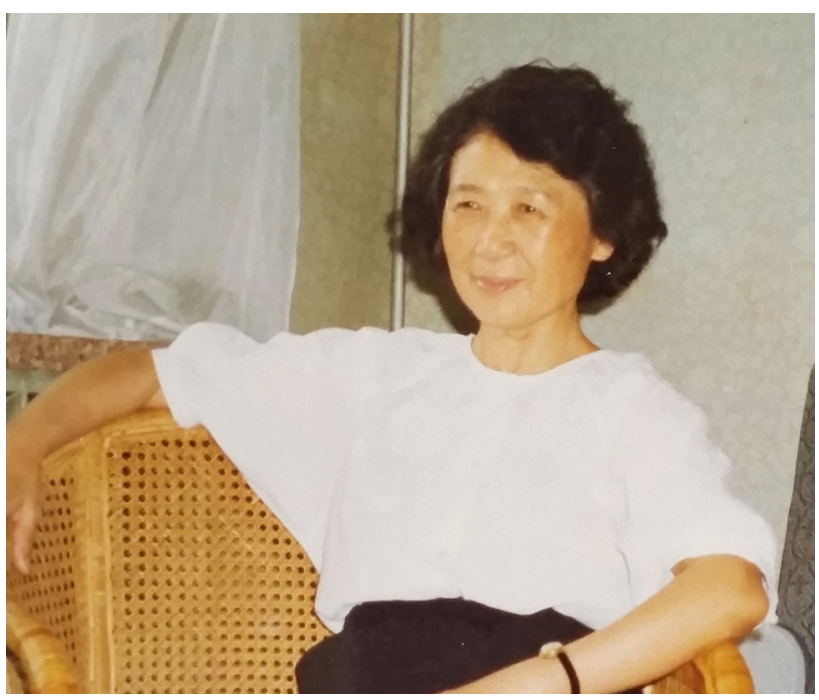

Fig. 1 Professor Tingyun Kuang

functional studies of light-harvesting pigment complexes. She was selected as an academician of the Chinese Academy of Sciences in 1995, and served as a member of the executive committee of the International Society of Photosynthesis Research during 1998-2004. She served a number of roles in national and international societies, including the president of the Botanical Society of China (1998-2002), honorary president of the Plant Physiology Society of China (2000-present), honorary president of the Botanical Society of China (2003-present), and academician of the International Academy of Sciences for Europe and Asia (2004-present). She also successfully organized the 15th International Congress on Photosynthesis in Beijing in 2010 with her colleagues.

Tingyun Kuang has focused her research on the structure and function of photosynthetic membrane protein 
complexes of various plants. Here major achievements can be summarized as follows.

1. The role of manganese in photosynthetic function Professor Kuang started her photosynthetic career from the effects of manganese on the Hill reaction, and found that the activity of oxygen evolution is closely related to the concentration of manganese (Cui et al. 1964). She also investigated the effects of manganese on photophosphorylation and observed that manganese acts on the non-cyclic photophosphorylation rather than the cyclic photophosphorylation (Kuang et al. 1966).

2. Structure and function of thylakoid membranes At the end of 1970s, Professor Kuang had an opportunity to visit the United States of America where she learnt the progress in photosynthesis research by visiting several famous photosynthesis laboratories. After returning back from USA, she decided to turn her research interests to the structure and function of photosynthetic membranes. She led her team to study the relationship between the structure and function of thylakoid membranes of plants and promoted the research in thylakoid membranes in China (Kuang et al. 1979; Lin et al. 1980; Li et al 1986; Wang and Kuang 1988; Wang et al. 1989; Zuo et al. 1991, 1992; Chen et al. 1993, 1994; Shi et al. 1997; Tang et al. 1999; Xu et al. 2000a, b).

3. Structure and function of the chlorophyll-protein complex of PSI

In 1981, Professor Kuang proved for the first time that the $21 \mathrm{kDa}$ chlorophyll-protein complex was the origin of the long-wavelength florescence emission band from PSI, while she was working in Charles J. Arntzen's Laboratory (Kuang et al. 1984). In 2006, she led her team to develop a novel method to isolate the large amount of PSI-LHCI complexes from spinach leaves with a relatively short time (Qin et al. 2006). Since a part of LHCII could be light-harvesting antennas for PSI, they tried to get PSI-LHCI-LHCII super-complex and studied its properties under high light conditions (Qin et al. 2011). Very recently, her team, in collaboration with Professor Jian-Ren Shen's team, successfully crystallized the PSI-LHCI complexes from Pisum sativum (pea) and solved its structure at a resolution of $2.8 \AA$ (Qin et al. 2015). This study provided a firm structural basis for the understanding on the energy transfer and photoprotection mechanisms within the PSI-LHCI super-complex.

4. The structure and function of chlorophyll-protein complex of PSII
In 1984, Professor Kuang, collaborated with DJ Kyle, found the movement consequence of its phosphorylation, thereby revealed the lateral migration of lightharvesting chlorophyll protein complexes in the thylakoid membrane as a means for regulation of excitation energy distribution between the two photosystems (Kyle et al. 1984). She also proposed the possible kinetic model of charge separation in the PSII reaction center (Yu et al. 1992; Kuang et al. 1993), discovered the photodamage of His residues and pheophytin $a$ in the PSII reaction center. She and her colleagues proposed a hypothesis for the physiological role of the second electron-transfer branch which is to protect the first branch against the excess excitation energy (Yu et al. 1994, 1995; Shan et al. 1999a, b; Wang et al. 1999). She also extended her research interests into the mechanism of water oxidation in PSII. In 1999, her team succeeded in predicting the binding mode of calcium in the water oxidation center (WOC) (Zhang et al. 2000). In the subsequent time, her research team reported spectral and functional studies on siphonaxanthin-type light-harvesting complex of photosystem II from Bryopsis corticulan (Chen et al. 2008; Wang et al. 2013). In 2004, her team collaborated with the research group led by Professor Wenrui Chang and reported the crystal structure of spinach light-harvesting complex (LHCII) at $2.72 \AA$ (Liu et al. 2004).

5. The structure and function of cytochrome $b_{6} f$ complex In 2001, Professor Kuang and her colleagues discovered the presence of 9-cis-carotene (Car) in cytochrome $b_{\sigma} f$ complex from spinach (Yan et al. 2001). They further found the presence of $\alpha$-carotene in the cytochrome $b_{6} f$ complex from a green alga Bryopsis corticulans ( $\mathrm{Li}$ et al. 2005). With this $\alpha$-Car-containing cytochrome $b_{6} f$ complex, they revealed the generation and mechanism of the high light-induced single oxygen and superoxide radical (Sang et al. 2010, 2011).

The functions of various photosynthetic systems have been studied extensively over several decades, and we have had a much deeper understanding on these functions at present. What appears to be less clear and equally important is the regulation mechanisms governing the functioning of various photosynthetic systems in vivo. It is for this reason that the international conference on "Regulation of Photosynthetic Functions" was organized, and this special issue is devoted. The special issue consists of 22 research papers and 4 review articles. The research papers cover a wide range of regulation and function of the photosynthetic systems from chloroplast gene expression, RNA editing and splicing, photoinhibition, photoprotection and repair of photosystem II, stability of apo-CP43, role of lipids in PSII 
analyzed by site-directed mutagenesis of D1, to the function of lanthanum(III) and cerium(III) ions on water oxidation, the role of PsbQ in PSII assembly, absorption and transfer of light energy by fucoxanthin-chlorophyll-binding proteins, early chloroplast development, photosynthesis under elevated $\mathrm{CO}_{2}$ conditions, metabolite signaling from mitochondrial alternative oxidase, binding and interaction of a large complex of $\mathrm{NAD}(\mathrm{P}) \mathrm{H}$ dehydrogenase with ferredoxin, and photochemical properties of rice leaves. The review articles include chlorophyll biosynthesis and assembly into the chlorophyll-binding proteins, protection of photosynthesis under abiotic stress conditions, proteomic analysis of Synechocystis sp. PCC 6803, and the photobiological hydrogen production and artificial photosynthesis for clean energy production. We believe that these contributions represent the state-of-the-art studies in this field, and will therefore greatly promote our understanding on the regulation of various photosynthetic systems.

Acknowledgments We thank all of the authors who contributed to this special issue. We are also grateful to our dedicated reviewers for their valuable comments and suggestions. In particular, we want to thank Dr. David Knaff, Editor-in-Chief of Photosynthesis Research, and Ellen Klink, Meertinus Faber, at Springer, Dordrecht, for their continuous help and support in developing this special issue.

\section{References}

Chen ZQ, Lin SQ, Tang CQ, Xu CH, Chen MQ, Kuang TY (1993) A study on the composition of membrane lipid of different thylakoid fractions from cucumber chloroplast. J Plant Physiol Mol Biol 3:293-298

Chen ZQ, Xu CH, Chen MJ, Xu L, Wang KB, Lin SQ, Kuang TY (1994) Effect of cold-hardening on thylakoid membrane lipids and proteins of spring wheat and winter wheat. Acta Bot Sin 36:423-429

Chen GY, Niu XD, Chen XB, Li LB, Kuang TY, Li SQ (2008) Characterization of chlorophyll-protein complexes isolated from a siphonous green alga, Bryopsis corticulans. Photosynth Res 96:75-81

Cui C, Kuang TY, Yang ZN (1964) Functions of manganese on photosynthesis. I. Effect of manganese on hill reaction. Acta Phytophysiol Sin 1:71-79

Kuang TY, yang ZN, Cui C (1966) Functions of manganese on Photosynthesis. I. Effect of manganese on photophosphorylation. Acta Phytophysiol Sin 14:139-143

Kuang TY, Zhang QD, Hao NB, Lou SQ, Li TZ, Zuo BY (1979) Structure and function of chloroplast membrane. Acta Phytophysiol Sin 2:100-107

Kuang TY, Argyrousi Akoyunoglou JH, Nakatani HY et al (1984) The origin of the long-wavelength fluorescence emission band $(77 \mathrm{~K})$ from photosystem I. Arch Biochem Biophys 235:618-627

Kuang TY, Yu ZB, Tang CQ, Lu RH, Peng DC, Tang PS (1993) Light induced damage of histidine residues in photosystem II reaction center D1/D2/cyt b559 complex. Acta Bot Sin $35: 246-248$
Kyle DJ, Kuang TY, Watson JL, Arntzen CJ (1984) Movement of a sub-population of the light harvesting complex (Lhcii) from grana to stroma lamellae as a consequence of its phosphorylation. Biochim Biophys Acta 765:89-96

Li TZ, Lou SQ, Lin SQ, Kuang TY (1986) Organization of reaction center and internal and peripheral antennae chlorophyll-protein complexes of photosystem II. Photobiochem Photobiophys 11:19-28

Li BX, Mao DZ, Liu YL, Li LB, Kuang TY (2005) Characterization of the cytochrome $\mathrm{b}(6) \mathrm{f}$ complex from marine green alga, Bryopsis corticulans. Photosynth Res 83:297-305

Lin SQ, Zhang QD, Lou SQ, Hao NB, Lin TZ, Kuang TY (1980) Structure and function of chloroplast membrane VI. Mg on the conversion of light energy and relative quantum yield of electron transport in thylakoid membranes. Acta Phytophys Sin 6:353359

Liu ZF, Yan HC, Wang KB, Kuang TY, Zhang JP, Gui LL, An XM, Chang WR (2004) Crystal structure of spinach major lightharvesting complex at 2.72 angstrom resolution. Nature 428:287-292

Qin XC, Wang KB, Chen XB, Qu YG, Li LB, Kuang TY (2006) Rapid purification of photosystem I chlorophyll-binding proteins by differential centrifugation and vertical rotor. Photosynth Res 90:195-204

Qin XC, Wang WD, Wang KB, Xin YY, Kuang TY (2011) Isolation and characteristics of the PSI-LHCI-LHCII supercomplex under high light. Photochem Photobiol 87:143-150

Qin X, Suga M, Kuang T, Shen JR (2015) Structural basis for energy transfer pathways in the plant PSI-LHCI supercomplex. Science 348:989-995

Sang M, Ma F, Xie J, Chen XB, Wang KB, Qin XC, Wang WD, Zhao JQ, Li LB, Zhang JP, Kuang TY (2010) High-light induced singlet oxygen formation in cytochrome $\mathrm{b}(6) \mathrm{f}$ complex from Bryopsis corticulans as detected by EPR spectroscopy. Biophys Chem 146:7-12

Sang M, Xie J, Qin XC, Wang WD, Chen XB, Wang KB, Zhang JP, Li LB, Kuang TY (2011) High-light induced superoxide radical formation in cytochrome b(6)f complex from Bryopsis corticulans as detected by EPR spectroscopy. J Photochem Photobiol B 102:177-181

Shan JX, Wang JS, Liu YL (1999a) The resonance Raman spectra of PSII core antenna complexes, CP43 and CP47. Chin Bull Bot 41:280-284

Shan JX, Yang KY, Li LB, Kuang TY (1999b) Purification and spectral characteristics of $\mathrm{CP} 43$ and CP47 from PSII core complex in spinach leave. Acta Biophys Sin 15:142-151

Shi H, Zhao NM, Tang CQ, Kuang TY (1997) Effect of chlorophyll a on the structure of two kinds of phospholipids under illumination-possible behavior of lipids in the photodamage process of photosystem II. Prog Nat Sci 7:723-728

Tang CQ, Zuo BY, Li GQ, Zhang Q, Jiang GZ, Feng LJ, Peng DC, Kuang TY (1999) Changes of chlorophyll-protein complexes and photosynthetic activities of chloroplasts from lotus (Nelumbo nucifera) seeds germinating in light. Acta Bot Sin 41:608-612

Wang WQ, Kuang TY (1988) A preliminary study on the orientation of pigment molecules within photosynthetic membrane. Acta Phytophys Sin 3:274-280

Wang WQ, Kuang TY, Tang PS (1989) Effects of unsaturated fatty acids on the orientation of photosynthetic pigments within photosynthetic membranes. Chin J Bot 1:64-72

Wang JS, Shan JX, Xu Q, Gong YD, Kuang TY, Zhao NM (1999) Light and heat induced denaturation of photosystem II core antenna complexes CP43 and CP47. J Photochem Photobiol B 50:189-196 
Wang WD, Qin XC, Sang M, Chen DQ, Wang KB, Lin RC, Lu CM, Shen JR, Kuang TY (2013) Spectral and functional studies on siphonaxanthin-type light-harvesting complex of photosystem II from Bryopsis corticulans. Photosynth Res 117:267-279

Xu CC, Kuang TY, Li LB, Lee CH (2000a) D1 protein turnover and carotene synthesis in relation to zeaxanthin epoxidation in rice leaves during recovery from low temperature photoinhibition. Aust J Plant Physiol 27:239-244

Xu CC, Lin RC, Li LB, Kuang TY (2000b) Photoprotection in chilling-sensitive and -resistant plants illustrated at chilling temperature: role of the xanthophyll cycle in the protection against lumen acidification. Aust J Plant Physiol 27:669-675

Yan JS, Liu YL, Mao DZ, Li LB, Kuang TY (2001) The presence of 9 -cis- $\beta$-carotene in cytochrome b6f complex from spinach. Biochem Biophys Acta 1504:396-408

Yu ZB, Kuang TY, Tang CQ, Zhang QD, Peng DC, Tang PS (1992) Photodamage of photosystem II reaction center D1-D2-cytochrome b559 complex. Acta Biophys Sin 8:634-652
Yu ZB, Li CC, Tang CQ, Kuang TY, Lu RH, Tang PS (1994) CD spectrum of D1/D2/Cyt b559 complex in damaged of photosystem II reaction center. Acta Bot Sin 8:603-606

Yu ZB, Kuang TY, Lu RH, Tang CQ, Tang PS (1995) Light induced damage of amino acid residues and degradation of polypeptides in D1/D2/CYTOCHROME B559 complex. Acta Bot Sin 4:401-404

Zhang CX, Pan J, Li LB, Kuang TY (2000) Theoretical investigation on peripheral ligands of oxygen-evolving center in photosystem II. Sci China (Ser C) 43:337-346

Zuo BY, Jiang GZ, Yu YL, Kuang TY (1991) Ultrastructural development of chloroplast in sacred lotus embryo bud under invisible light. Acta Bot Sin 33:169-175

Zuo BY, GQ LI, Tang CQ, Jiang GZ, Kuang TY (1992) Changes of thylakoid membrane stacks and $\mathrm{Chl} \mathrm{a} / \mathrm{b}$ ratio of chloroplast from sacred lotus (Nelumbo nucifera) seeds during their germination under light. Acta Bot Sin 9:645-650 